\title{
The Relationship Between Art Theory and Design Education
}

\author{
Peng Jin \\ Art History Department of Art and Design College \\ Wuhan University of Technology \\ Wuhan, China \\ e-mail: 68844929@qq.com
}

\begin{abstract}
The relationship between art theory and design education is an important topic which involves the aesthetics accomplishment of the artist, expanding the cultural horizon, and improving the personal ability to create artworks. However, there has been a long time since the discussion of this topic was stopped. In the current cultural environment where the art and design discipline is increasingly growing fast, we should pick up this topic and get over the complicated relationship between them, and review the important role that the art theory plays from the view of art development, to build a cultural platform for the art thinking and the design theory to communicate and develop with each other.
\end{abstract}

Keywords-art theory, design education, aesthetics ideal, design style innovation

In the history of Chinese and Western art education, the relationship between art theory and design practice has always been a topic worth continuously discussing. From the Qin Dynasty, the art creation was concluded in the "Confucian Analects - Shu $\mathrm{R}$ " as follows: "Let the will in conformity with the truth; Let every attainment in morality be firmly respected; Let perfect virtue be accorded with; Let relaxation and enjoyment be found in the fine arts." This not only accurately summarizes the art practice, but also prioritizes each element of the art creation. That is to say, the art creation firstly decided by the spirit, which is the objectification of metaphysical spirit. Truth here can be interpreted as "objective law" or eternal Spirit Entity. Only when we get a deep insight into the Truth, can we realize the voluntary compliance with the ethics and social constraints derived from the perfect virtue, and finally reach the free realm and the highest level of the art creation: "Let relaxation and enjoyment be found in the fine arts", and reach a sentimental sublimated state of the mind - to create artworks in an ideal condition of "forgetting all" with a completely freedom aesthetic mentality. However, what's the Truth for art practice? It's a rather important theoretical proposition. Combining with the contextual history of the art culture development, the art theory, as the general sum-up for the art creation and the appreciation rules, is one of the core elements of the art and the design practice. However, art theory itself is not a simple concept but a theory system with a very large structure. Its theoretical value is the core to correctly understand the development of art theory and the relationship between the art theory and the design practice.

In a wide sense of the art theory, it includes art history, art theory and art criticism; in a narrow sense of the word, it's an individual concept like the art history and art criticism, mainly exploring the basic theoretical problems such as art creation, the basic appreciation rules, art development, anthropology of art, art appreciation, psychological mechanism of the art creation and appreciation, art acceptance, and more. In this paper, the art theory refers to the concept in a wide sense. As a theory system of the art field, it's necessary for the students majored in the art and design to have an full grasp of the contextual history of the art's birth and development, and to understand the internal driving force of the art's historical evolution. The levels of the understanding of the art theory will affect the spiritual trend and cultural purport of the art and design practice, and are related to art taste and cultural spirit of the design works. Therefore, as the specific embodiment for the metaphysical art spirit, the art theory plays an important role in the art and design teaching. As a practitioner of the design teaching, we should always adopt the teaching principle to deeply understand that the art theory is the important carrier of our spiritual civilization, to better instruct our teaching practices and to make the art theory combined with the art and design practice.

If we review the relationship between the theory and the art design practice from a historical view, we can easily find that, the Chinese thinkers had been looking into this theoretical proposition for a long time and had taken numerous constructive theory explorations and trials. This has a great impact on the future trend of the Chinese art aesthetics. There are many examples of the art aesthetic viewpoint affecting the trend of the design style in "Confucian Analects". For example, the Confucius said, "I hate the manner in which purple takes away the luster of vermilion. I hate the way in which the songs of Zheng confound the music of the Ya. I hate those who with their sharp mouths overthrow kingdoms and families", based on the moral ration and social ideals of "subduing one's desire and returning to the Truth". It takes Confucianism as the principle and clearly demonstrates the Confucian viewpoints and the culture philosophy of LiYue. This not only deeply affected the aesthetic ideal of color ideal at that time, but also enriched the spiritual significance of Chinese design philosophy and extended the cultural vision of the traditional design symbols. We can take another example from the "Confucian Analects": "In the last month of spring, with the dress of the season, along with five or six young men, enjoy the breeze and the rain in altars, and return home with singing. The Confucius said that I give my approval to them." It demonstrated the extremely great cultural idea of the Confucian aesthetics and the aesthetic dimensions of the morality and accomplishment. All of these added fuel to the flames of the LiYue Culture in the Chinese classical aesthetics and the design.

As for the German classical aesthetics, in the book of "Letters upon the Aesthetic Education of Man ", Schiller advanced many brand-new theoretical propositions. These propositions played a theoretical enlightenment role in the process for the Western art to transform from luxury style of the Rococo era to the bourgeois art 
style. Schiller pointed out that the purpose of the art education was to shape "a complete personality". In his book, he analyze that the intrinsic root of art education by comparing the culture conditions of the ancient Greeks and the current society. He had rethought the cultural spirit of the French Revolution from the historical cultural view. In his opinion, the French Revolution was not successful and did not truly realize the social ideal and people's will of freedom. The revolution of politics and economics could not help people no longer "dance with shackles", but the aesthetics education could. He also pointed out that, "we should prioritize the aesthetics before the freedom", "We must use the method of aesthetics education to resolve the political issues. People can only get freedom with the help of aesthetics" . He got an aesthetic conclusion from these opinion, "people play games only if they really were people; people are complete people only if they played games". Based on the comprehensive analysis of the anthropology and the art history, he came up with the conception of the relationship between art and freedom. His theory is the important conclusion in German classical aesthetics. It not only has a huge impact on the art theory and art practice in the 19th century in the Europe, but also significantly drive the transformation of the Western visual art creation. The Classicalism, Romanticism, Symbolism and the birth of the Impressionist all benefit from his theoretical contribution. In the modern times of China, Yuanpei Cai is the first one to advocate the idea of "Relying upon Aesthetic Education Instead of Religion". He had brought up the purpose of the education - "Education can cultivate healthy personality" and "Develop the spirit of Republic". He explained that, "A healthy personality should have four kinds of education, they are physical education, intelligence education, moral education, and aesthetics education. These four points are equally important, and we should focus on all of them". He criticized the shackles which the feudal education placed on people's thinking and development, and advocated the theory of the four kinds of educations mentioned above as a whole to cultivate all-round talents, driving the ideological liberation of Chinese people. His thoughts have a profound impact on China's modern art and design culture. Besides of these, as the president of the Peking University at that time, he strongly supported the art education practices. The first national art college in China was founded in this cultural environment. Additionally, the Association of Painting in Peking University was founded by Yuanpei Cai in March, 1918, which became the important place for them to discussing the development of Chinese art theory and practice. He took the cultural undertaking seriously with the spirit of free thinking, helped some excellent artists like Fengmian Lin and Haishu Liu study abroad, which objectively accelerated the exchange between Chinese and Western art spirit, making a great contributions to the Modernization of the arts of China.

In the design history of the Western world, The Arts and Crafts Movement is a successful example of art theory driving the art style's changes. In the middle of 19th century, the design industry in the Western world was rather depressed. On the surface, the evolution of the design thinking could not catch up with the European industrial revolution. But the root was the disruption caused by the industrial revolution. The art spirit had made room for the unprecedented productivity brought by the industrial production. To save the design industry, the famous art theorist Ruskin brought up with his idea - the compromise in the design style was the result of indefinite exaggeration of the industrialization. We must find the path for the design industry to communicate with the Western art tradition, in order to get the prosperity of the design civilization back. Especially when he had visited The Great Industry Exhibition of All Nations in UK, he was not surprised with the modern industrial revolution results embodied by the Crystal Palace but rather disgusted. He thought the Giant Greenhouse made of glasses and steels deviated from the tender spirit of the western design art. He said it's necessary to introduce the traditional Western art theory to resolve the current problem, and denied the difference between the Big Art and the Small Art. He advocated the artists to engage in design and to bring the theory of humanistic into the design field. His theory had excited strong reaction in the Western art industry and drove many young artists engage into the design improvement movements. Many artists who had profound influence to the Western design industry, like William Morris, Father of Modern Design and Dante Rossetti, the leading artist of Pre-Raphaelite Brotherhood were among them. They unified some artists and started The Arts and Crafts Movement. In the final analysis, Ruskin's theory brought up with the important idea that the art theory decide the design's development. In addition to this, the influence of his theory made a judgment and position for the Western design development. Therefore, his theory is an important chapter in art theory which is worth understood by the modern designers.

It's indisputable that art theory can significantly drive the design creation. In the design field, it's firstly applied to the teaching practice in the Bauhaus in Germany. Gropius, the first president of this college, engaged many Abstractionism artists as the teachers like Kandinsky, John Eaton, Paul Klee, Munch and Feininger. Most of them were avant-garde artists. They had successfully introduced the latest art theories and art styles into the education practice in Bauhaus. Particularly, Kandinsky was not only an Abstractionism artist, but also an art theorist. "The Spirit of Arts" wrote by he in 1911 was recognized as the classic theory of the modern arts. Shouzhi Wang pointed out that, "Kandinsky thinks the future art is supposed to be a combination of multiple media, not a single media, which he calls Gesamtkunstwerk process. This German word may be translated not so accurately into the combination of the art creations. This terminology was not created by Kandinsky. It was firstly used by the German musician Wagner, Kandinsky was the first person to use it in the creation and education of visual arts. In 1921, when he was still in the Expressionist group Blue Rider, he had already supported this assumption. From this assumption and view, he became the important co-worker of Gropius without doubt." In Shouzhi Wang's point of view, Kandinsky's creative understanding of modern arts concept helped him get strong theoretical supports in the field of design education revolution. To some extent, there are some commons in arts and design as the visual arts. In the early $20^{\text {th }}$ century, the theoretical innovation of the arts was ahead of the design industry without doubt. The design style at that time was basically consistent with the arts style. So the identity of arts theorist helped Kandinsky become the important originator of the Western modern design. As for this, Shouzhi Wang also pointed out that, "Another reason why Gropius engaged Kandinsky is that he is an extremely excellent art theorist. He is very knowledgeable from arts to physics, and has a profound grasp of all these knowledge, and digest and integrate them. This is very important for the new design education."

Besides of this, Bauhaus made an experimental arrangement in the design courses settings, which not only focused on the teaching of the design techniques, but also on greatly improving the theoretical attainments of the students and encouraging them to develop the ability to feel and create beauty in a multi-dimensional manner. The courses in Bauhaus can be categorized into "required fundamental courses, optional fundamental courses, industrial technology fundamental courses, and art theory courses (art history, philosophy, design theory, etc.)" With the diversity in the design idea, and allowing hundreds of cultural thoughts involved, 
therefore,Bauhaus become the cradle of the European Modernism design and the laboratory for the modern design education .

As the systematical conclusion of the objective rules, the art theory is the important component of the design practice education, thus the discipline construction of the art theory needs to be strengthened. Just as Congwen Shen pointed out in his book "The Education of Art" published during the period of Republican China, "There are few schools that were equipped with excellent library and art gallery, and can engage teachers who study the dynastic history of the art of this country and have a grasp of the general art. Few art education practitioners could broaden the vision of the students and sublime their personalities and emotions. One can imagine the results of teaching with so little interest in teaching and so limited knowledge." From a different view, the education situation for the art design discipline in China is not optimistic. More and more students shift their interests in the design technology. The main studying direction has been changed to learn how to make full use of the design software. No doubt technical operation is essential for students majoring in design to study, but if we take the technology as a standard, it's a kind of behavior of confusing the primary with secondary. Design behavior is a kind of creation activity after all, and is a kind of cultural behavior to carry out the spiritual innovation consciously. If you cannot have a grasp of the content of the design aesthetics ideal, it's far from the successful design.

In nowadays, many students majored in design do not realize the importance of the art theory courses. The art theory as the fundamental course has begun to reach a state of marginalization. To reverse such trend, every design education practitioner should clearly realize the seriousness of this problem. In addition to this, we also should expand our commitment to this discipline not only in the scientific research funds, but also in the continuous engagement of a large number of professionals into our team of the art theory study, in order to rationalize the age of our academic team and enrich the theoretical study directions of our academic team and the expertise structures. Only if we have a strong academic team, can we carry out the theoretical innovation and produce more academic results continuously. Moreover, we should carry out the social research on the design aesthetics to drive the design move towards a more rationalized, more orderly and more scientific direction, establishing a solid foundation for the innovation of the design style in China and the progress of the art theory study.

\section{REFERENCES}

[1] Kai Zhuge, "Ten Lecture In Design". Shandong pictorial press,Jinan,2006, pp.19

[2] Confucius, "Confucian Analects". Zhonghua book company, Beijing,2006, pp.13,39,58

[3] Friedrich von Schiller, "Letters upon the Aesthetic Education of Man", China's literature federation press, Beijing,1984, pp.83,90

[4] Yuanpei Cai, "The Selected Aesthetic Papers". Peking university press,Beijing,1983, pp.107

[5] Shouzhi Wang,"The History of Modern Design". Chinese youth publishing house,Beijing,2002, pp.149,151 